\title{
Incidence, distribution pattern and HIV/AIDS occurrence among tuberculosis patients attending DOTS centre in a Nigerian Teaching Hospital
}

\author{
A. Winifred OJIEABU ${ }^{1}$, IH. Uchenna EZE ${ }^{1^{*}}$, N. Mbang FEMI-OYEWO ${ }^{2}$ and \\ S. Titilola AKIYODE ${ }^{1}$ \\ ${ }^{I}$ Department of Clinical Pharmacy and Biopharmacy, Faculty of Pharmacy, Sagamu, Olabisi Onabanjo \\ University, Ago Iwoye, Ogun State, Nigeria. \\ ${ }^{2}$ Department of Pharmaceutics and Pharmaceutical Technology, Faculty of Pharmacy, Sagamu, Olabisi \\ Onabanjo University, Ago Iwoye, Ogun State, Nigeria. \\ *Corresponding author, E-mail: ifyeze3000@yahoo.com, Postal address- Box 557 Juli House Post Office \\ Ikeja, Lagos, Nigeria. Tel: + 2348055481547, +2347060627667
}

\begin{abstract}
Mycobacterium tuberculosis infection is still a devastating disease with an alarming rate of increase in prevalence, morbidity and mortality. HIV/AIDS infection has also dramatically increased tuberculosis (TB) prevalence as it accounts for the greatest number of AIDS presenting illnesses. A retrospective study was carried out to determine the TB incidence, pattern of distribution and HIV/AIDS among patients reporting for treatment at the DOTS clinic of Olabisi Onabanjo University Teaching Hospital (OOUTH) Sagamu from 2005 to 2007. TB incidence for the 3 years was 315 of which the highest number 119 (37.7\%) occurred in 2007. The age range 25-34 years (29.52\%) had the highest number of respondents and $50.5 \%$ of the patients were females. Mean age \pm SD were $19.69 \pm 17.44$. Majority of the patients $(95.2 \%)$ had pulmonary TB. Two hundred and seventy (85.4\%) were new patients, 43 (13\%) were relapsed patients and $2(0.6 \%)$ were transferred patients. There was no significant statistical difference between incidence and age $(\mathrm{p}=0.5051)$, distribution pattern of the disease $(\mathrm{P}=0.8206)$, but a significant difference occurred between incidence and sex $(\mathrm{p}=0.0333)$. HIV/AIDS occurrence was highest $37(35 \%)$ among the patients in 2006. Our findings revealed a steady increase in TB incidence for the period under review and HIV/AIDS occurrence though high was not statistically significant.

(C) 2010 International Formulae Group. All rights reserved.
\end{abstract}

Keywords: Tuberculosis, Incidence, HIV/AIDS

\section{INTRODUCTION}

Tuberculosis (TB) is a common and often deadly infectious disease caused by mycobacteria mainly, Mycobacterium tuberculosis (Kumar et al., 2007). The causative organism is transmitted exclusively by inhalation of infective droplets from patients with open pulmonary tuberculosis through coughing, sneezing, talking or spitting (Johnston et al., 1974). In 2004, mortality and morbidity statistics included 14.6 million chronic active cases, 8.9 million new cases, and 1.6 million deaths, mostly in developing countries (WHO, 2006a). World Health 
Organization estimated that 9.2 million new cases of TB occurred in 2006 (139 per 100 000), including 4.1 million (62 per 100) new smear-positive cases. In terms of incidence cases, India, China, Indonesia, South Africa and Nigeria rank first to fifth, respectively. In all these global cases, Africa accounts for $31 \%$ while Asia accounts for $55 \%$ of the cases (WHO, 2008).

The prevalence, patterns of presentation and mortality from tuberculosis have been known to vary from one country to another and from one region of a country to the other. This variation depends on prevailing social factors such as socio-economic status of the people, malnutrition, crowded living conditions, incidence of HIV/AIDS, level of development of health infrastructures, quality of available control-programmes and degree of drug resistance to anti-tuberculous agents among other factors (Cancroff et al., 1993; Delock, 1994).

The advent of HIV/AIDS infection has also dramatically increased its prevalence as it accounts for the highest number of AIDS presenting illnesses (Dye et al., 2005) and also there is rising incidence of $\mathrm{TB}$, especially pulmonary TB in HIV-infected patients. HIV infection has contributed significantly to the resurgence of TB especially in the subSaharan Africa (Busi et al., 2004; Elizinga et al., 2004).

In a ten-year review (Erhabor et al., 1993) (1991-2000) of patterns of presentation and outcome of pulmonary tuberculosis in Obafemi Awolowo University Teaching Hospitals Complex, Ile-Ife, the case records of 308 pulmonary TB patients were analyzed for pattern of socio-demographic distribution, clinical and radiological presentation, outcome of treatment and factors associated with mortality. The results showed that presentation peaked in the third and fourth decades and poor living conditions were significant risk factors in patients. The study concluded that attention should be paid to improving the living standard conditions of the people and health education and treatment be made free or subsidized.

In a similar review in Edo state (Salami et al., 2007), pulmonary tuberculosis accounted for $87 \%$ followed by abdominal tuberculosis $(3.5 \%)$ and disseminated tuberculosis $(2.5 \%)$.

In another study (Akinyoola et al., 2007), a retrospective review of all patients with tuberculosis of the spine was carried out, 24 males $(49 \%)$ and 25 females $(51 \%)$ with a mean age of 32.8 were reported to be infected but students $(30.6 \%)$ and traders $(26.5 \%)$ were the most affected groups. Human immunodeficiency Virus (HIV) screening was confirmed positive in $2(7.4 \%)$ out of 27 patients that had the test.

Since tuberculosis has become a major public health burden, studies like this should be conducted in all the states of the federation in order to sensitize the government to increase political will in the fight against this scourge. The main purpose of this study was to determine TB incidence, pattern of distribution and HIV/AIDS occurrence among patients attending directly observed therapy short course (DOTS) centre at the Olabisi Onabanjo University Teaching Hospital, Sagamu, Ogun State.

\section{MATERIALS AND METHODS Study location}

This study was conducted at the DOTS centre of Olabisi Onabanjo University Teaching Hospital (OOUTH), Sagamu, Ogun State which is located at the Southwestern Nigeria and acts as a referral centre to many primary and secondary health institutions both within and outside the state.

\section{Data collection}

A pre-tested and validated data collection format designed by the authors was 
used for data collection. The DOTS register containing information of patients treated for tuberculosis between January 2005 and December 2007 in OOUTH, Sagamu was retrieved for data collection. Data extracted included age, sex, address, TB type, tests used for diagnosis, treatment status (new, relapse and transferred in) and HIV status which was then entered into the structured data collection form.

\section{Ethical consideration}

Permission to carry out the research was obtained from the ethical committee of Olabisi Onabanjo University Teaching Hospital, Sagamu, Ogun State.

\section{Limitations}

The limitations included incomplete data in the register such as occupation and educational level.

\section{Data analysis}

Epi-info 2002 was used for data entry, validation and analysis. Chi-square test was applied for the comparison of proportions and evaluation of association of categorical variables as well as Graph pad Instat for oneway ANOVA test. Statistical significance was set at $\mathrm{P}<0.05$.

\section{RESULTS}

A total of 315 TB patients were reported at the OOUTH DOTS centre between the periods of 2005-2007. The highest number of patients (119 $(37.8 \%)$ reporting was in 2007 while the least, 90, $(28.6 \%)$ was in 2005. The females had the highest number $(50.5 \%)$ overall although males had the highest number of incidence in two consecutive years (2006 and 2007) with 56.6\% and 52\% respectively while the females took the lead in 2005 with 62\%. There was statistical significance between sex and TB incidence $(\mathrm{P}$-value $=0.0333)$ as shown in Table 1.

Age range 25-34 years, mean age \pm SD $19.69 \pm 17.44$ had the highest incidence while the lowest was recorded in the age group above 65 years. There is however no statistical significance difference between age and TB incidence $(\mathrm{P}$-value $=0.5051$, Table 2$)$. Pulmonary TB was the most frequently $(95.2 \%)$ seen among the patients with the highest $(98.1 \%)$ recorded in 2006 as against $92.2 \%$ in 2005 while extra-pulmonary type gave insignificant values of $8 \%, 1.9 \%$ and $5 \%$ respectively for the three years ( Table 3 ).

HIV occurrence among the patients was highest (35\%) in 2006 and lowest (19\%) in 2005 although it was $27 \%$ rate over all. There is however no statistical significance ( $\mathrm{p}$ value $=0.9180$ ) as shown in Table 4 .

The number of new patients reporting for treatment at the DOTS Clinic was 270, $(85.4 \%)$ while relapsed cases was $13 \%$ and those transferred in from other centers was just 2, $(0.6 \%)$ (Table 5).

Table 1: Sex distributions of TB patients for the period of study.

\begin{tabular}{lllll}
\hline Gender & $\mathbf{2 0 0 5}$ & $\mathbf{2 0 0 6}$ & $\mathbf{2 0 0 7}$ & Total frequency $(\boldsymbol{\%})$ \\
& Frequency $(\boldsymbol{\%})$ & Frequency $(\boldsymbol{\%})$ & Frequency $(\boldsymbol{\%})$ & \\
\hline Male & $34(38.0)$ & $60(56.6)$ & $62(52.0)$ & $156(49.5)$ \\
Female & $56(62.0)$ & $46(43.4)$ & $57(48.0)$ & $159(50.5))$ \\
Total & $\mathbf{9 0}(\mathbf{1 0 0})$ & $\mathbf{1 0 6}(\mathbf{1 0 0})$ & $\mathbf{1 1 9}(\mathbf{1 0 0})$ & $\mathbf{3 1 5}(\mathbf{1 0 0})$ \\
\hline
\end{tabular}


Table 2 : Age distribution of TB patients.

\begin{tabular}{llll}
\hline Age range & $\begin{array}{l}\text { Male } \\
\text { N= 156 } \\
\text { Frequency (\%) }\end{array}$ & $\begin{array}{l}\text { Female } \\
\text { N= 159 } \\
\text { Frequency (\%) }\end{array}$ & $\begin{array}{l}\text { Total } \\
\text { N=315 } \\
\text { Frequency (\%) }\end{array}$ \\
\hline$<10$ & $12(7.7)$ & $6(3.8)$ & $18(5.7)$ \\
$10-14$ & $2(1.3)$ & $5(3.1)$ & $7(2.2)$ \\
$15-24$ & $29(18.6)$ & $40(25.2)$ & $69(21.9)$ \\
$25-34$ & $45(28.8)$ & $48(30.2)$ & $93(29.5)$ \\
$35-44$ & $39(25.0)$ & $36(22.6)$ & $75(23.8)$ \\
$45-54$ & $18(11.5)$ & $15(9.4)$ & $33(10.5)$ \\
$55-65$ & $9(5.8)$ & $6(3.8)$ & $15(4.8)$ \\
$>65$ & $2(1.3)$ & $3(1.9)$ & $5(1.6)$ \\
Total & $\mathbf{1 5 6}(\mathbf{1 0 0})$ & $\mathbf{1 5 9}(\mathbf{1 0 0})$ & $\mathbf{3 1 5}(\mathbf{1 0 0})$ \\
\hline \multicolumn{2}{c}{$\mathrm{X}^{2}=6.30, \mathrm{df}=7, \mathrm{p}-\mathrm{value}=0.5051$} & &
\end{tabular}

Table 3: Type and gender distribution pattern for TB incidence from 2005-2007.

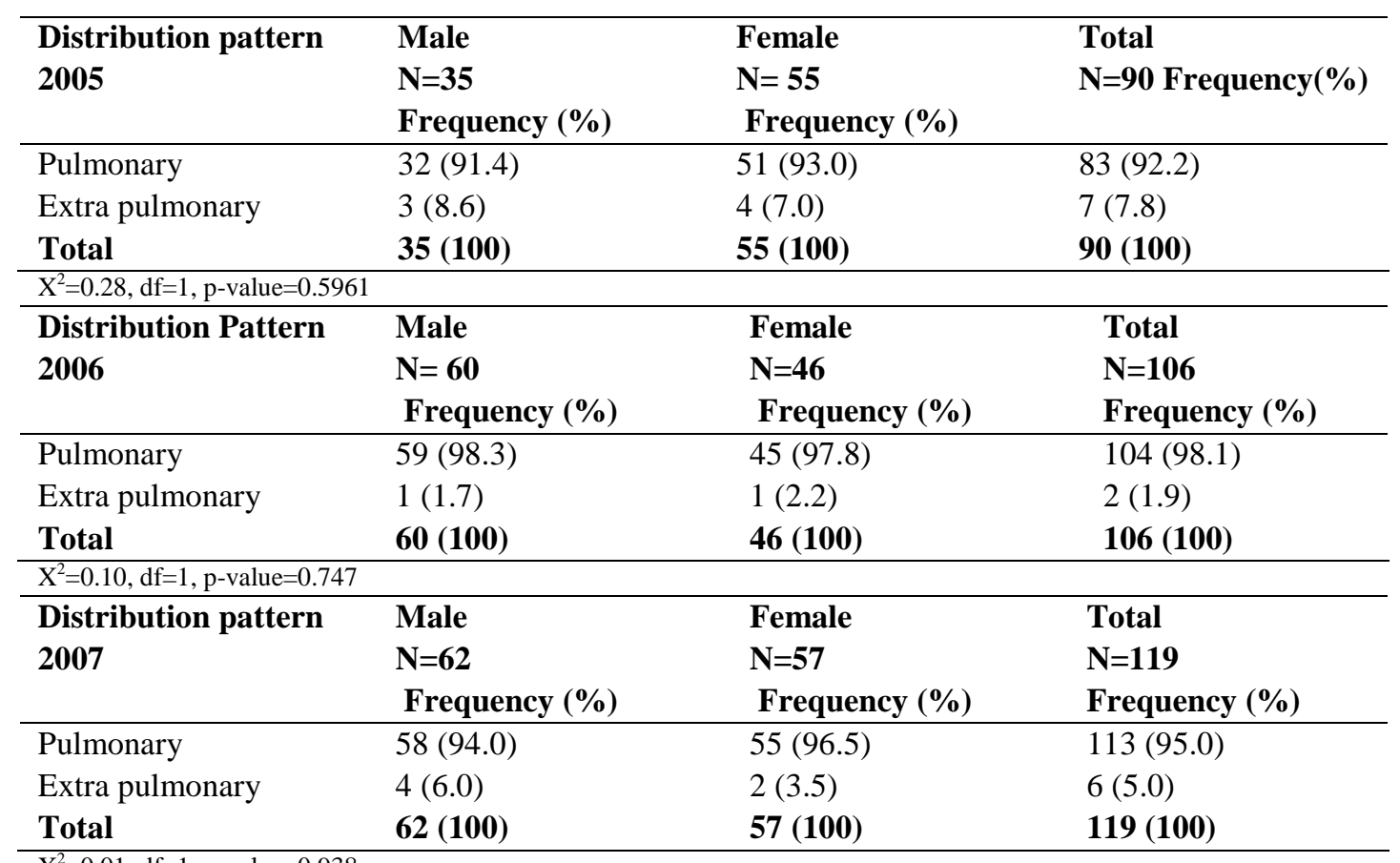

$\mathrm{X}^{2}=0.01, \mathrm{df}=1, \mathrm{p}$-value $=0.938$

Table 4: HIV status of TB patients.

\begin{tabular}{lllll}
\hline Status & $\mathbf{2 0 0 5}$ & $\mathbf{2 0 0 6}$ & $\mathbf{2 0 0 7}$ & Total \\
& N=90 & N=106 & N=119 & N=315 \\
& Frequency $(\boldsymbol{\%})$ & Frequency $(\boldsymbol{\%})$ & Frequency $(\boldsymbol{\%})$ & Frequency (\%) \\
\hline HIV Positive & $17(19.0)$ & $37(35.0)$ & $32(27.0)$ & $86(27.3)$ \\
HIV Negative & $73(81.0)$ & $69(65.0)$ & $87(73.0)$ & $229(72.7)$ \\
Total & $\mathbf{9 0}(\mathbf{1 0 0})$ & $\mathbf{1 0 6}(\mathbf{1 0 0})$ & $\mathbf{1 1 9}(\mathbf{1 0 0})$ & $\mathbf{3 1 5}(\mathbf{1 0 0})$ \\
\hline
\end{tabular}

One way ANOVA test: $\mathrm{F}=0.8810, \mathrm{p}=0.9180$ 
Table 5: Categories of TB patients on treatment.

\begin{tabular}{llll}
\hline Category & $\begin{array}{l}\text { Male } \\
\text { N= 156 } \\
\text { Frequency (\%) }\end{array}$ & $\begin{array}{l}\text { Female } \\
\text { N=159 } \\
\text { Frequency }(\%)\end{array}$ & $\begin{array}{l}\text { Total } \\
\mathbf{N}=\mathbf{3 1 5} \\
\text { Frequency (\%) }\end{array}$ \\
\hline New & $129(83.0)$ & $141(89.0)$ & $270(85.4)$ \\
Relapse & $25(16.0)$ & $18(11.0)$ & $43(13.0)$ \\
Transfer in & $2(1.0)$ & 0 & $2(0.6)$ \\
Total & $\mathbf{1 5 6}(\mathbf{1 0 0})$ & $\mathbf{1 5 9}(\mathbf{1 0 0})$ & $\mathbf{3 1 5}(\mathbf{1 0 0})$ \\
\hline
\end{tabular}

$\mathrm{X}^{2}=2.30, \mathrm{df}=2, \mathrm{p}$-value $=0.1617$

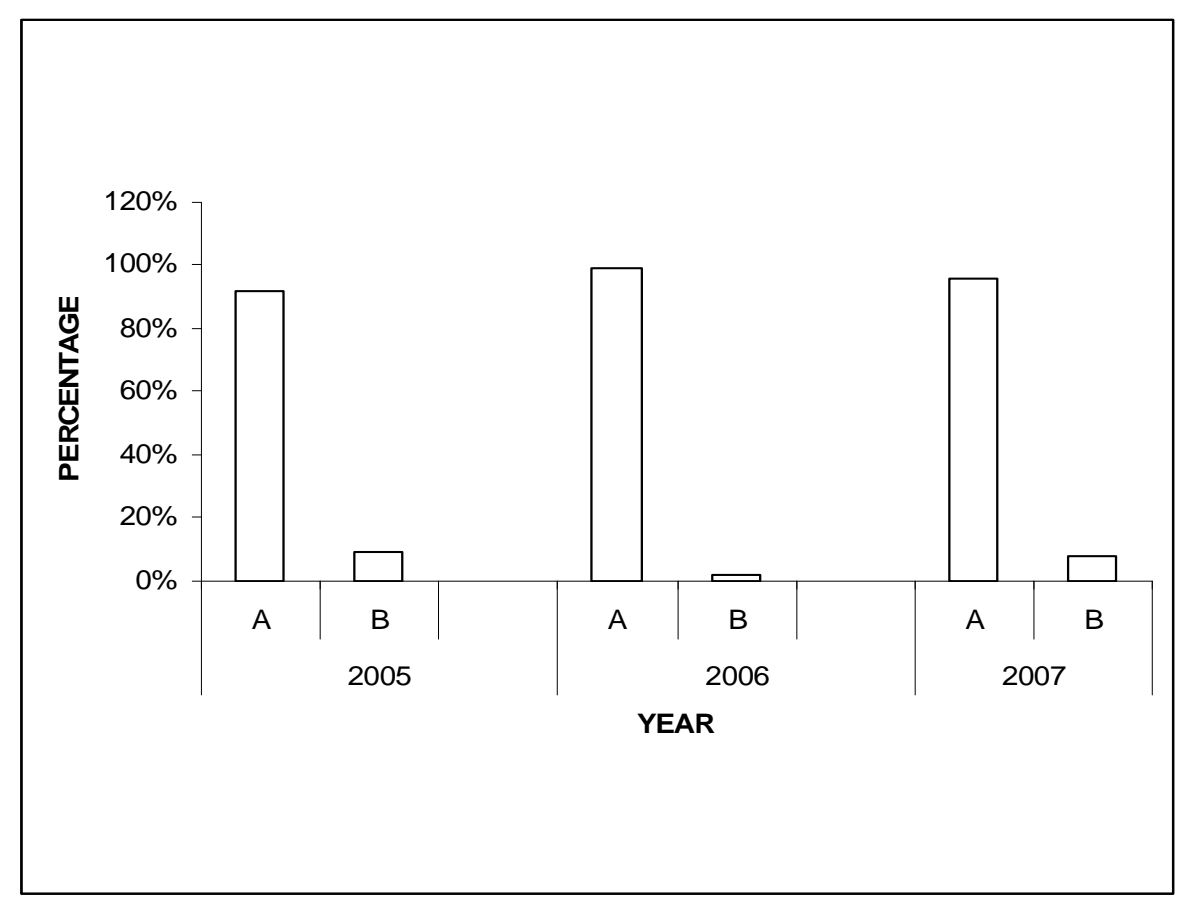

Figure 1: TB Incidence and distribution from 2005 to 2007.

$\mathrm{A}=$ Pulmonary tuberculosis; $\mathrm{B}=$ Extra- Pulmonary tuberculosis.

\section{DISCUSSION}

In this study, it was found that pulmonary tuberculosis was the most predominant type that recorded a result similar to previous studies (Odetunde et al., 1999; Salami et al., 2007) and steadily increased with each year.

TB incidence was slightly higher in the females compared to the males with a statistical significance. This is in contrast with a previous study (Salami et al., 2007) where there was no sex difference. Some studies however recorded a slightly higher male population than that of the females (Okoduaet al., 2004; Erah and Oghenevware, 2009). Although it has been reported in most parts of the world that more men than women are diagnosed with $\mathrm{TB}$ and die from it, WHO (2005) revealed that every year, over 3 million women contact TB and the disease is a leading cause of death among them. The disease predominantly affected those in the first, second and third decades of life which is consistent with a study by Salami et al (2007) 
in which the disease also predominantly affected those in their first, third and fourth decades of life. This presentation pattern is the one mostly seen in developing countries like Nigeria where above $75 \%$ of TB cases were in age group less than 50 years compared to developed countries where those affected were mostly above 50 years. (Ahlburg, 2005). The age groups mostly affected are those who are actively engaged in pursuit of one endeavor or the other and are the most economically vibrant.

A high incidence of HIV (27\%) coexistence with TB showing a close association between the two infectious diseases was recorded in this study. This finding differs from a study (Okodua et al., 2004) where the incidence of HIV/TB co-existence was $9.6 \%$ but similar to that of the national HIV infection rate among adult TB patients in Nigeria which was also estimated to be $27 \%$ by the WHO (2005). States like Borno, Plateau and Benue were also reported by the Federal Ministry of Health to have HIV/TB prevalent rates of $27 \%, 30 \%$ and $35 \%$ respectively (FMH, 2000). Higher HIV prevalence rates of $30-50 \%$ have also been found in TB patients in cities of developed countries (Brudney et al., 1991; Heckbert et al., 1992). Tuberculosis resurgence has been attributed significantly to HIV infections, poverty and social deprivation (Bare et al., 1999) and WHO estimated that nearly 10 percent of new TB patients are HIV positive (WHO, 2009).

Those receiving treatment at the DOTS Centre comprised predominantly new patients. These may be patients who reported on their own to the hospital or directed by friends/relatives to seek help in the hospital. Clinical data in Nigeria shows that the incidence of TB is on the increase (WHO, 2006b). Among other factors are those which are attributed to failure to detect a huge number of active TB cases which may primarily be responsible for the spread of the infection. Failure of national tuberculosis programmes to detect the vast majority of new infectious cases suggests that active screening strategies should be re-evaluated in an attempt to improve case detection and thereby increase access to TB treatment (Murray et al., 1998).

\section{Conclusion}

Our findings revealed a steady increase in TB incidence, predominantly pulmonary type and female preponderance for the period under review. Co-existence of TB and HIV was non-insignificant. Tuberculosis incidence is still very high and alarming and needs every form of possible aggressiveness. Even though the high over-all co-existence of TB and HIV was statistically insignificant, it must still be viewed with great concern which should necessitate serious enlightenment campaign efforts to eradicate these twin devastating diseases.

\section{REFERENCES}

Ahlburg D. 2000. The economic impacts of TB. World Health Organization, Geneva. (documentWHO/CDS/STB/2000.5,http:// www.stoptb.org/conference/ahlburg.pdf) (Accessed on 19/9/2005).

Akinyoola AL, Adegbehingbe OO, Ashaleye CM. 2007. Tuberculosis of the spine in Nigeria, Has anything changed? The Internet Journal of Third World Medicine, 4: 1 .

Bare PF, Havlir DV. 1999. Tuberculosis in patients with human immunodeficiency virus infection. The New England Journal of Medicine, 340: 367-3.

Brudney K, Dobkin J. 1991. Resurgent tuberculosis in New York City. Human immunodeficiency virus, homelessness and the decline of tuberculosis control programmes. Am. Rev. Respir. Dis., 144: 745-749.

Busi Rizzi E, Schinina V, Palmieri F, Girardi E, Bibboline C. 2004. Cavitary pulmonary tuberculosis HIV-related. Eur. J. Radiol., 52: 170-174.

Cancroff ET, Montorfano D, Wadhwa N. 1993. Pulmonary tuberculosis, a resurgence of an old disease. Postgraduate Radiology, 13: 198-217. 
Delock K. 1994. The new tuberculosis. African Health., 16: 8-10.

Dye C, Watt C, Bleed D, Hossaini S, Raviglione M. 2005. Evolution of tuberculosis control and prospects for reducing tuberculosis incidence, prevalence, and deaths globally. JAMA., 293: 2767-2775.

Elzinga G, Raviglione MC, Mahar D. 2004. Scale-up: Meeting targets in global tuberculosis control. Lancet, 363: 814 -9.

Erah PO, Oghenevware LO. 2009. Success of DOTS Programme in a tertiary health care facility in Southern Nigeria. Journal of Chemical and Pharmaceutical Sciences, 2: 4.

Erhabor GE, Adebayo RA, Omodara JA, Famurewa OC. 2003. Ten year review of patterns of presentation and outcome of pulmonary tuberculosis in OAUTH, IleIfe. Nigerian Journal of Health Sciences, 3: 34-37.

Federal Ministry of Health (FMH). 2000. Tuberculosis and Leprosy Control effects in Nigeria. National Tuberculosis and Leprosy Control Programme (NTBLCP).

Heckbert SR, Elart A, Nolan CM. 1992. The impact of human immunodeficiency virus infection in young men in Seattle-King country. Washington Chest, 102: 433437.

Johnston RE, Wildrick KH. 1974. "State of the art" Review. The impact of chemotherapy on the care of patients with tuberculosis. Am. Rev. Resp. Dis., 109: 636-664.

Kumar Vinay, Abass Abul k, Aousto N, Mitchell RN. 2007. Robins Basic Pathology ( $8^{\text {th }}$ edition $) ; 516-522$.
Murray CJ, Salomon JA. 1998. Expanding the WHO tuberculosis control strategy: rethinking the role of active case-finding. Int. J. Tuberc. Lung. Dis., 2(1): S9-15.

Odetunde NA, Akinfolarin AA, Peter O, Odebola AY. 1999. Tuberculosis and its complications. The Ibadan Experience. Dokita., 26(1): 33-35.

Okodua MA, Nwobu GO, Tatfeng YM, Ongey JY, Agwu E. 2004. Incidence of HIV - related pulmonary tuberculosis in Edo State, Nigeria. Shiraz E-Med J., 5(1): 1-12.

Salami TAT, Samuel SO, Eze KC, Oziegbe OE. 2007. Tuberculosis in a Nigerian Teaching Hospital: incidence and pattern of distribution. The Tropical Journal of Health Sciences., 14(2): 25-30.

WHO (World Health Organization). 2005. http://www.who.int/tb/dots/gender/page_ 1 /en/index.html. Accessed 1/10/2005.

WHO (World Health Organization). 2006a. Tuberculosis fact sheet N 104. Global and regional incidence. Retrieved on $6^{\text {th }}$ Oct. 2006.

WHO (World Health Organization. 2006b). Global Tuberculosis Control. WHO Report Geneva.

WHO (World Health Organization). 2008. Global Tuberculosis Control. WHO Report 2008. The Organization, Geneva.

WHO (World Health Organization). 2009. Global TB database and country profiles. Available from: http://www.who.int/tb/ country/global_tb_database/en/index2.ht ml. Accessed 7 December 2009. 